\title{
Identification and explanation of the factors related to knowledge management in Supreme Audit Court
}

\author{
Professor Dr. Sorush Niknamian \\ Board Member of Weston A Price Foundation, Washington Dc, USA \\ E-mail: so.niknamian@gmail.com
}

\begin{abstract}
The purpose of this study is to identify and explain the factors related to knowledge management. The present research is applied in the field of applied research. It is a descriptive research and survey method based on a questionnaire tool. In this research, firstly, through the study of previous studies and studies, a relatively comprehensive understanding of the literature in this field was obtained and, accordingly, a preliminary list of knowledge management factors as well as its components and indicators were provided. Then these factors were completed and finalized using content analysis and Delphi methodology. The statistical population of this research, in the Delphic Phase, 30 experts and at the stage of factor analysis, 199 managers Court of Auditors in different categories. The findings of the main components analysis using one-sample t-test and Chi-square test showed that the factors related to knowledge management include leadership, culture, technology, education, human resources, activities and processes, and infrastructure. After confirming the relationship of each of these factors with knowledge management, using Pearson correlation coefficient, we have provided practical suggestions for improving and improving knowledge management.
\end{abstract}

Key words: Knowledge Management Factors, Calculation Tribunal, Delphi Method

\section{Introduction}

In recent years, knowledge has been recognized as a key organizational resource and the foundation for sustainable development, especially in highly competitive environments that experience widespread and discrete radical changes. Yet, there are many organizations drowned in a huge amount of information, but they are still hungry for knowledge (Kamas, 2008); therefore, in today's economy, knowledge has been replaced by financial and physical capital as the most important capital. The significance of knowledge in new era necessitated the organization to turn to the application of re-engineering and modernization of strategies, processes and technologies in line with the knowledge management perspective (Rivra, 2016). Currently, many companies and organizations in the worldwide have invested in knowledge management. However, despite some success, many of these organizations experienced a number of failures (Kiara Hoyne and Frederick Adam, 2012). It seems that a wide range of situations and challenges contribute to the successful or final failure of $\mathrm{KM}$ activities in the organization, so before investing these scarce resources in such a risky area, management should be looking for tools to reduce the uncertainty of the KM project. In addition, the lack of proper mechanisms for assessing the organization's current status for implementing knowledge management, or the development of KM activities has caused some managers to suspect that this type of investment alone is an additional cost and brings no benefit to the organizations. Thus, for purposeful application of knowledge as a competitive and strategic advantage, as well as organizing the stages of knowledge management development in an organization, understanding the organization's existing conditions in the field of knowledge management and determining the factors affecting an organization's decision making for the implementation and improvement of knowledge management seem essential and vital (Cans, 2013). Since the Supreme Audit Court is one of the institutions affiliated to the Islamic Consultative Assembly which is responsible for overseeing all the 
financial processes of the country and acting as the parliamentary oversight arm, it seems that the leverage of knowledge management is one of the most important tools of the tasks assigned to this system and the development and management of knowledge have been explicitly mentioned in the strategic plan, perspectives, goals and priority of the strategy of the country's supreme audit court as well. Therefore, the main objective of the present research is to identify the factors related to knowledge management in the country's supreme audit court so as to maximize the utilization of existing knowledge and to create new knowledge with respect to these factors.

Therefore, the research questions presented are as follows:

What are the factors associated with knowledge management?

What is the status of the factors associated with knowledge management?

What is the relation between factors related to knowledge management with knowledge management?

\section{Theoretical foundations and research literature}

Most people and experts in the field of knowledge management believe that three categories of human element, culture, and technology play a major role in the implementation of knowledge management projects. In the early stages of the knowledge management project, there was a focus mostly on technology and, consequently, the same thoughts of knowledge management with technology. Many of the companies and organizations that have invested heavily in technology in knowledge management projects have failed, because they did not pay attention to two other dimensions that were more important than the technology dimension. Culture has a significant impact on both dimensions. The basic underpinnings of knowledge management are based on people, culture and technology. Most experts seem to have the opinion that $80 \%$ of knowledge management success relate to people and culture while the remained 20\% depend on technology. The cultural and public dimensions of knowledge management are rooted in organizational behavior, human resource management, and management principles. The third component, i.e., technology is based on artificial intelligence, knowledge engineering, information technology, librarianship and information systems (Leibovitz, 2009, p. 17). This idea was also supported by Davenport on the factors associated with knowledge management. According to Davenport, people, processes and technology are the three key components of any organizational environment. Knowledge management puts an emphasis on individuals and organizational culture in order to create a spirit of sharing and knowledge use. It also focuses on processes, or practices for generating, acquiring, and sharing knowledge, as well as relies on technology for the storage and capturing of knowledge and its usability when working together (without the physical presence of people). Individuals play an increasingly important role in knowledge management because they have a direct dependence on people's willingness to share and use knowledge. Individuals, processes, and technology can always be viewed as either a stimulating factor or an obstacle to the knowledge development. They always identified and eliminated the barriers as well as expanded and created incentives (Nowroozi and Abdul Majid, 2008, pp. 105-106). Some people looked knowledge management from another point of view. For example, Sharma and Wickramasinghe identified four infrastructural factors for knowledge management: necessary infrastructure for collaboration, the infrastructure needed to build organizational memory, human resources infrastructure, and knowledge network (Dohani, 2008, P. 194). Stankoosky and Baldetra (1999) also introduced organizational culture, organizational structure, technology, leadership, and learning as the success factors of knowledge management program (Attarpoor, 2009, pp. 28-29). In their research, Rezaiean et al. (2013), examined the indicators of knowledge management such as organizational culture, information technology, human resources, leadership, organizational structure and internal processes as well as e-learning indicators including computer-based education, network based education, network learning, virtual classrooms and digital collaboration. They came to the conclusion that the effectiveness of knowledge management is at desirable level in e-learning. In a similar study, Salehi et al., (2013) have evaluated the required infrastructure from different aspects and appropriate conditions for deploying a knowledge management system in the organization under study. Their results indicated that the seven components considered for the deployment of knowledge management including organizational culture, organizational structure, information technology, knowledge acquisition, knowledge transfer, knowledge use and knowledge maintenance, have appropriate conditions. Shahcheragh and Shahmirzai (2012) 
investigated the feasibility of implementing a system and knowledge management systems in this network in the human resource dimension through the variables familiar with the knowledge position and the necessity of knowledge management, the ability to identify, store, document knowledge resources, motivation among groups for sharing knowledge, organizing knowledge, ability to share knowledge, application of knowledge. The findings of their research revealed that some of the feasibility variables assigned were assessed less than moderate level and some more than average in the human

resource dimension. In addition, technical and financial feasibilities were examined through exploratory interviews with senior executives, both of which were modest. Bahrami et al., (2011) have studied the feasibility of implementing a knowledge-based structure. The results of their analysis showed that the viewpoint of female employees is higher than that of male employees working at the Faculty regarding the basic assumption. In the main hypothesis, the average of the highest scores was found among employees with a work experience of 11-15 years and the lowest among employees of 1-5 years. During the implementation of $\mathrm{KM}$, the highest and lowest scores were observed among employees with a $\mathrm{PhD}$ in relation to the main hypothesis.

\section{Method}

To perform the study, the author initially obtained a relatively comprehensive understanding of the literature in this field through the study of previous history and research, and on this basis, provided a preliminary list of KM factors as well as its components and indicators. These factors were then completed by using content analysis approach and Delphi methodology. Identified factors associated with knowledge management are presented in Table 1 with their references.

\section{1. Delphi method}

In this section, the indicators derived from the research literature and content analyses of the interviews were completed using the Delphi method. The Delphi technique is a method of gaining group knowledge. This process has a predictive structure and helps to make decision-making in the survey. This method includes the main question about the existence or absence of an indicator. The Delphi method seeks to aggregate opinions from a diverse set of experts, or effective factors identified. In this method, experts should have five characteristics of knowledge, experience in the subject, willingness, time, and communication skills. The most important factor in Delphi's approach is to reach consensus. The consensus is defined as an opinion or position reached by a group as a whole. Although it is impossible to reach a full consensus on any matter, to achieve a consensus more than half (51\%) seems sufficient.

The consensus stages are as follows:

\section{Study books and articles to identify factors:}

Prior to beginning the research, the factors related to knowledge management in the country's audit court were prepared as a survey through a study on various articles. This survey introduces 36 factors in 7 dimensions.

- Selection of Experts: 30 specialists and PhD experts in management from Kerman, Tehran, Isfahan, Mashhad and Shiraz were selected

- A Survey of Experts on Form No. 1: Using this form, experts gave a response to determine the impact of each factor and every one of the 30 questions. Then, it was asked the experts to specify certain other indicators that are important in their own opinion and write the reason for selecting each of the factors at the end of the survey form.

Table 4: Delphi results to examine the dimensions of knowledge management

\begin{tabular}{|l|l|l|l|l|l|}
\hline Dimensions & Mean & $\begin{array}{l}\text { Standard } \\
\text { deviation }\end{array}$ & t Statistics & $\begin{array}{l}\text { Significance } \\
\text { level }\end{array}$ & $\begin{array}{l}\text { Percentage of } \\
\text { agreement of }\end{array}$ \\
\hline
\end{tabular}




\begin{tabular}{|l|l|l|l|l|l|}
\hline & & & & & experts \\
\hline Leadership & 4.500 & 0.682 & 36.125 & 0.000 & 90 \\
\hline Culture & 4.600 & 0.621 & 40.542 & 0.000 & 93.3 \\
\hline Technology & 4.467 & 0.681 & 35.902 & 0.000 & 90 \\
\hline Education & 4.567 & 0.679 & 36.842 & 0.000 & 90 \\
\hline Human resources & 4.533 & 0.629 & 39.487 & 0.000 & 93.3 \\
\hline Activities and processes & 4.500 & 0.731 & 33.714 & 0.000 & 86.7 \\
\hline Infrastructure & 4.333 & 0.802 & 29.583 & 0.000 & 86.7 \\
\hline
\end{tabular}

Based on the results, $\mathrm{t}$ is greater than 1.96 in all components, so all the components related to knowledge management are confirmed by the professors.

4. Summarizing and preparing a questionnaire: experts and specialists scored between 1 and 9 for each of the determined factors and all the specified indicators have scores higher than 6 by using the t-test (from 1 to 9), so all the identified indicators were considered as relevant. Accordingly, a questionnaire was prepared.

5. Final questionnaire: Since all indicators had a score of 6 , the researcher confirmed the indices using the results obtained in the previous step. Using an open questionnaire of experts' questionnaire on the introduction of knowledge management factors by experts in the field of management, as well as the confirmation of the supervisor, the final questionnaire consisting of 37 indicators in 8 main headings was prepared and items related to each indicator were scored based on 5-point Likert scale as follows.

Table 6: The coding method for the items of the final research questionnaire

\begin{tabular}{|l|l|l|l|l|}
\hline Strongly disagree & Disagree & Neither agree nor disagree & Agree & Strongly agree \\
\hline $\mathbf{1}$ & $\mathbf{2}$ & $\mathbf{3}$ & $\mathbf{4}$ & $\mathbf{5}$ \\
\hline
\end{tabular}

\section{2. Reliability of the questionnaire}

Using Cronbach Alpha is one of the ways to calculate reliability. This method is used to calculate the internal consistency of measuring instruments such as questionnaire. To assess reliability, a questionnaire was firstly distributed among 30 members and was analyzed after collection. The reliability coefficient ranges from 0 to 1 and the closer the correlation coefficient (r) is to 1.00 the greater the reliability. If the alpha value is greater than 0.7 , it indicates a good reliability and values less than 0.6 are undesirable. Using SPSS18 software, the confidence interval was calculated using Cronbach's alpha; the results of which are shown in the table below indicating the good reliability of the questionnaire.

Table 7: Results of reliability

\begin{tabular}{|l|l|l|}
\hline Dimensions & Cronbach's alpha \\
\hline \multirow{4}{*}{ Related factors for knowledge management } & Leadership & $\mathbf{0 . 8 9 5}$ \\
\cline { 2 - 3 } & Culture & $\mathbf{0 . 9 0 2}$ \\
\cline { 2 - 3 } & Technology & $\mathbf{0 . 9 4 7}$ \\
\cline { 2 - 3 } & Education & $\mathbf{0 . 9 5 1}$ \\
\cline { 2 - 3 } & & $\mathbf{0 . 9 2 5}$ \\
\cline { 2 - 3 } & Human resources & $\mathbf{0 . 9 3 5}$ \\
\cline { 2 - 3 } & Activities and processes & $\mathbf{0 . 9 1 3}$ \\
\cline { 2 - 3 } & Infrastructure & \\
\hline
\end{tabular}

\section{3. Fitness of Measurement Patterns (convergent and divergent validity)}

To evaluate the convergent validity of measuring instruments, the average extracted variance (AVE) has been used, which its results are shown in Table 8. An acceptable value for the average extracted variance (AVE) has been estimated at least 0.4 (Neonaly \& Brestin, 1994). 
Table 8: Convergence of Measurement Tools (Questionnaires)

\begin{tabular}{|l|l|}
\hline Variable & Average extracted variance (AVE) \\
\hline Leadership & $\mathbf{0 . 5 3 1}$ \\
\hline Culture & $\mathbf{0 . 4 9 2}$ \\
\hline Technology & $\mathbf{0 . 7 1 2}$ \\
\hline Education & $\mathbf{0 . 6 4 4}$ \\
\hline Human resources & $\mathbf{0 . 7 8 4}$ \\
\hline Activities and processes & $\mathbf{0 . 7 3 7}$ \\
\hline Infrastructure & $\mathbf{0 . 6 4 3}$ \\
\hline Related factors for knowledge management & $\mathbf{0 . 7 0 1}$ \\
\hline Acceptable value & $\mathbf{0 . 4}$ \\
\hline
\end{tabular}

The above table of values shows that the used questionnaires have a good convergent validity. In divergent validity, the difference between the indices of a structure and those of other structures of the model is compared. To do this, one must create a matrix whose principal values are the root of the AVE coefficients of per structure and the lower values of the original diameter are considered the coefficients of correlation between per structure with other structures. In fact, divergent validity is obtained from comparing the correlation of a structure with its indicators against the correlation of that structure with other structures. The method by Fornell and Larker (1981) provides a matrix whose correlation values on its main diameter should be greater than its underlying ones, indicating that the structures (latent variables) interact more with their own indicators rather than other structures. In other words, the divergent validity of the model is appropriate. This matrix is shown in Table 9:

Table 9: Divergent Validity of Measurement Tools (Questionnaires)

\begin{tabular}{|l|l|l|l|}
\hline Variable & 1 & 2 & 3 \\
\hline 1. Leadership & 0.73 & & \\
\hline 2. Culture & 0.54 & 0.71 & \\
\hline 3. Technology & 0.19 & 0.70 & 0.84 \\
\hline
\end{tabular}

The values of the table above indicate that the root of the AVE coefficients of per structure is higher than the correlation coefficients of that structure with other structures showing the acceptability of the divergent validity of structures.

\section{4. Statistical population}

The statistical population of this study for the preparation of the questionnaire composed of 30 experts and professors of the university with a Ph.D. in management.

The statistical population for the questionnaire measurement included 199 directors of the country's court of auditor in different ranks; according to Morgan's table, the sample size was considered 127 directors.

\section{Findings}

\section{5. 1. Variable description of factors related to knowledge management}

The variable of factors related to knowledge management consisted of 36 items in 5 options. The average observed for this variable is (3.54), its median (3.64), mode (3.50), standard deviation (0.54), minimum (2.33) and maximum (4.83). For a better interpretation of the mean, the scoring scale presented by Abbas Bazargan et al. was used, which is presented in Table 10 (Bazargan et al., 1999, p. 13). According to the empirical mean (3.54) and based on Abbas Bazargan et al., we can conclude that the variable of factors related to knowledge management has been assessed more than satisfactory.

Table 10: Descriptive statistics of variable related to knowledge management among respondents

\begin{tabular}{|l|l|l|l|l|l|l|}
\hline Number & Mean & Median & Mode & $\begin{array}{l}\text { Standard } \\
\text { deviation }\end{array}$ & Minimum & Maximum \\
\hline 127 & 3.54 & 3.64 & 3.50 & 0.54 & 2.03 & $4 / 83$ \\
\hline
\end{tabular}


Table 11: Scoring Scale by Abbas Bazargan et al

\begin{tabular}{|l|l|l|l|l|l|l|}
\hline Very strong & strong & Good & $\begin{array}{l}\text { More than } \\
\text { satisfactory } \\
\text { level }\end{array}$ & satisfactory & $\begin{array}{l}\text { Neither } \\
\text { strong nor } \\
\text { satisfactory }\end{array}$ & Unsatisfactory \\
\hline $4.51-4.99$ & $4.01-4.49$ & $3.61-3.99$ & $3.01-3.59$ & $2.51-2.99$ & $2.01-2.49$ & less than 2.00 \\
\hline
\end{tabular}

\section{5. 2. Description of the variable components of factors related to knowledge management}

The descriptive information of the variable components of the factors related to knowledge management, including mean, median, mode, standard deviation, minimum and maximum are presented in Table 12. For a better interpretation of the mean, the scoring scale presented by Abbas Bazargan et al. was used, which is presented in Table 4-9 (Bazargan et al., 1999, p. 13). Based on the empirical means as well as the scale presented by Abbas Bazargan et al., we can conclude that the components of culture, technology, human resources, activities, processes and infrastructure are more than satisfactory level, and the components of leadership and education are at a good level.

Table 12: Descriptive statistics of variable components of factors related to knowledge management among respondents

\begin{tabular}{|l|l|l|l|l|l|l|l|}
\hline Component & $\begin{array}{l}\text { Numbe } \\
\text { r }\end{array}$ & Mean & Median & Mode & $\begin{array}{l}\text { Standard } \\
\text { deviation }\end{array}$ & Minimum & $\begin{array}{l}\text { Maximu } \\
\text { m }\end{array}$ \\
\hline Leadership & 127 & 3.79 & 3.90 & 4.00 & 0.62 & 1.90 & 5.00 \\
\hline Culture & 127 & 3.49 & 3.56 & 3.44 & 0.63 & 1.56 & 5.00 \\
\hline Technology & 127 & 3.59 & 4.00 & 4.00 & 0.77 & 1.25 & 5.00 \\
\hline Education & 127 & 3.65 & 4.00 & 4.00 & 0.74 & 1.00 & 5.00 \\
\hline $\begin{array}{l}\text { Human } \\
\text { Resources }\end{array}$ & 127 & 3.20 & 4.00 & 4.00 & 0.89 & 1.00 & 5.00 \\
\hline $\begin{array}{l}\text { Activities and } \\
\text { processes }\end{array}$ & 127 & 3.13 & 4.00 & 4.00 & 0.83 & 1.00 & 5.00 \\
\hline Infrastructure & 127 & 3.44 & 4.00 & 4.00 & 0.74 & 1.67 & 5.00 \\
\hline
\end{tabular}

Table 13: Scoring Scale by Abbas Bazargan et al

\begin{tabular}{|l|l|l|l|l|l|l|}
\hline Very strong & strong & Good & $\begin{array}{l}\text { More than } \\
\text { satisfactory } \\
\text { level }\end{array}$ & satisfactory & $\begin{array}{l}\text { Neither } \\
\text { strong nor } \\
\text { satisfactory }\end{array}$ & Unsatisfactory \\
\hline $4.51-4.99$ & $4.01-4.49$ & $3.61-3.99$ & $3.01-3.59$ & $2.51-2.99$ & $2.01-2.49$ & less than 2.00 \\
\hline
\end{tabular}

\section{5. 3. Normality of the Distribution of Research Variables}

H0: The variables of the model follow the normal distribution.

H1: The variables of the model do not follow the normal distribution.

Distribution of data is one of the important presuppositions for investigating research questions and hypotheses in statistical tests. If the data have a normal distribution, parametric tests can be used to test hypothesis and nonparametric tests are used if no normal assumption is made. Using skewness and kurtosis coefficients of research variables is one of the ways to examine the distribution of data. By this assumption, the data are normal which their critical ratio is at a distance of (2.85 and -2.85) (Karshekie, 2012 and Klein, 2011). As can be seen, all coefficients are obtained at a distance of (2.85 and -2.85); therefore, this assumption is confirmed for all factors related to knowledge management. Parametric statistical tests can be also employed for examining the questions of this research.

Table 14: the Normality of Research Variables

\begin{tabular}{|l|l|l|l|l|}
\hline Variable & Skewness & Critical value & kurtosis & Critical value \\
\hline
\end{tabular}




\begin{tabular}{|l|l|l|l|l|}
\hline & coefficient & & coefficients & \\
\hline Leadership & -0.613 & -2.246 & 0.571 & 1.679 \\
\hline Culture & -0.505 & -2.238 & 0.174 & 0.407 \\
\hline Technology & -0.790 & -1.674 & 0.653 & 1.529 \\
\hline Education & 0.032 & -1.800 & 1.153 & 1.042 \\
\hline Human Resources & -0.211 & -1.981 & -0.633 & -1.482 \\
\hline Activities and processes & -0.216 & -1.004 & -0.559 & -1.309 \\
\hline Infrastructure for for & 0.523 & -2.432 & -0.447 & -1.047 \\
\hline $\begin{array}{l}\text { Related factors } \\
\text { knowledge management }\end{array}$ & -0.443 & $-2-060$ & 0.062 & 0.145 \\
\hline
\end{tabular}

3. 5. 4. Examining the status of related factors in knowledge management in the studied population H0: Factors related to knowledge management in the population under study are not in a desirable situation.

H1: Factors related to knowledge management in the population under study are in a desirable situation. As can be seen in Table 15, since the p-value of the test (0.001) is less than the significant level (0.05), the null hypothesis is then rejected and the population studied is at a desirable level. In other words, according to the average obtained for this variable and the indicator by Abbas Bazargan et al., the factors related to knowledge management in the studied population have been assessed more than satisfactory.

Table 15: Status of related factors in knowledge management in the studied population

\begin{tabular}{|l|l|l|l|l|}
\hline \multirow{2}{*}{} & \multirow{2}{*}{ Mean } & Standard deviation & \multicolumn{2}{l|}{ Theoretical average $=3.00$} \\
& & & & \multicolumn{2}{l|}{} \\
\cline { 3 - 5 } & & & p-value & $\mathrm{t}$-Statistics \\
\hline Related factors for knowledge management & 3.54 & 0.54 & 11.27 & \\
& & & & \\
\hline Leadership & 3.79 & 0.62 & 14.47 & 0.001 \\
\hline Culture & 3.49 & 0.63 & 8.71 & 0.001 \\
\hline Technology & 3.59 & 0.77 & 8.63 & 0.001 \\
\hline Education & & & & \\
\hline Human Resources & 3.65 & 0.74 & 9.99 & 0.001 \\
\hline Activities and processes & 3.20 & 0.89 & 2.55 & 0.006 \\
\hline Infrastructure & 3.13 & 0.83 & 1.80 & 0.037 \\
\hline
\end{tabular}

\section{5. Ranking of factors related to knowledge management in the studied population}

As can be seen in Table 16, since the p-value of the test (001/0) is less than the significant level (0/05), the null assumption is then rejected and the claim that the rank of classes is identical cannot be accepted, so it can be said that the leadership has the highest rank among the components of knowledge management factors in the studied population and education and technology components are in the next places.

Table 16: Ranking of factors related to knowledge management in the studied population

\begin{tabular}{|l|l|l|l|l|}
\hline Components & Rank & Average rank & $\begin{array}{l}\text { Chi-square } \\
\text { statistic }\end{array}$ & P-value \\
\hline Leadership & 1 & 4.88 & & \\
\cline { 1 - 3 } & 4 & 3.96 & & \\
\hline Technology & 3 & 4.73 & & \\
\hline
\end{tabular}




\begin{tabular}{|l|l|l|l|l|}
\hline Education & 2 & 4.76 & \multirow{2}{*}{134.361} & \multirow{2}{*}{0.001} \\
\hline Human Resources & 6 & 3.10 & & \\
\cline { 1 - 3 } Activities and processes & 7 & 2.63 & & \\
\cline { 1 - 2 } & 5 & 3.94 & & \\
\hline
\end{tabular}

\section{5. 6. The relationship between factors related to knowledge management and knowledge management}

Pearson correlation coefficient was used to study the relationship between variables (quantitative and normal data). The results of the correlation test show that there is a significant relationship between the components of leadership, culture, technology, education, human resources, activities and processes and infrastructure with knowledge management ( $\mathrm{p}$-value <0.05). Because correlation coefficients are calculated positively, these relations are of direct type (incremental). According to calculated correlation coefficients, it can be said that the relationship between activities and processes and knowledge management is of high intensity.

Table 17: Relationship between components of factors related to knowledge management and knowledge management

\begin{tabular}{|l|l|l|l|l|l|l|l|l|}
\hline Variable & $\mathbf{1}$ & $\mathbf{2}$ & $\mathbf{3}$ & $\mathbf{4}$ & $\mathbf{5}$ & $\mathbf{6}$ & $\mathbf{7}$ & $\mathbf{8}$ \\
\hline 1. Knowledge management & 1 & & & & & & & \\
\hline 2. Leadership & 0.390 & 1 & & & & & & \\
\hline 3. Culture & 0.729 & 0.541 & 1 & & & & & \\
\hline 4. Technology & 0.734 & 0.189 & 0.509 & 1 & & & & \\
\hline 5. Education & 0.723 & 0.226 & 0.587 & 0.514 & 1 & & & \\
\hline 6. Human resources & 0.666 & 0.411 & 0.688 & 0.651 & 0.630 & 1 & & \\
\hline 7. Activities and processes & 0.747 & 0.392 & 0.630 & 0.607 & 0.590 & 0.652 & 1 & \\
\hline 8. Infrastructure & 0.724 & 0.22 & 0.508 & 0.551 & 0.540 & 0.531 & 0.694 & 1 \\
\hline
\end{tabular}

** Significance level of $0.01, *$ Significance level of 0.05

\section{Conclusion}

Knowledge management, and subsequently knowledge management systems, came into being as the biggest phenomenon after emergence of "reengineering" and "comprehensive quality management". There are many common points between knowledge management with innovations in managerial skills and organizational learning. Knowledge management was firstly focused on information systems and then shifted its focus to organizational management development, intellectual intelligence capital and management skills. Investigating and analyzing the knowledge and the importance of its characteristics in the field of organizational performance indicate that the availability of updated knowledge and information has become an indispensable necessity for the survival of organizations. Specially, through the accurate evaluation of the process of change and developments in the society knowledge, it can be inferred that the post-industrial society is today the information society in which advanced technologies will be gradually replaced by knowledge-intensive technologies. The purpose of this study was to identify and explain the factors related to knowledge management and their measurement in the country's auditing court. Therefore, after studying literature and identifying the factors affecting the success of knowledge management, the author examined the relationship between factors related to knowledge management and knowledge management, as well as evaluation of the status of factors related to knowledge management and prioritizing these factors in the country's auditing court. The findings of this research suggest that the factors related to knowledge management included leadership, culture, technology, education, human resources, activities, processes and infrastructure, among which components of culture, technology, human resources, activities and processes and infrastructure were more than satisfactory and components of leadership and education were assessed at a desirable level. In 
addition, the results of the correlation test showed that there is a significant relationship between leadership, culture, technology, education, human resources, activities, processes and infrastructure components with knowledge management. Leadership refers to the need for the active and comprehensive support of the organization's leadership in implementing the KM system. For this purpose, it is recommended for administrators to facilitate the creation of an organizational mental model among employees on how to collaborate and share knowledge in order to generate knowledge while transferring it. According to the role of the culture factor in knowledge management, it is suggested to provide an appropriate cultural setting for creating, developing, and sharing knowledge in various ways, such as publishing brochures and holding seminars on how to manage knowledge in the organization, as well as approving and encouraging employees. Furthermore, it is essential for organizations to build this culture among their employees that everyone should adopt knowledge management role in the organization. The next factor in KM was technology. Based on the findings of this study, it can be suggested that the use of updated technologies, as well as the updating of useful information, can provide an appropriate platform for the acquisition and application of up-to-date and modern knowledge for members of the organization. In addition, in order to guide individuals to access the information they need, the appropriate tools and ecommerce facilities should be offered. Education is the next factor related to knowledge management. Based on this finding, it is suggested that continuous and directional training courses related to knowledge management be incorporated into employee's in-service training. Human resources are the next effective factor in knowledge management. In this regard, more attention should be paid to how to select and appoint the employees who are willing to manage their knowledge. The role of the next factor i.e., activities and processes,

was also identified and approved for knowledge management in the country's court of audit. According to this finding, it is suggested that all processes and organizational activities be carefully reviewed as well as modify what is in conflict with the creation and sharing of knowledge, and to strengthen and improve what it helps to manage knowledge in the organization. Infrastructure is another confirmed factor related to knowledge management. Based on the results, it is suggested that the technical infrastructure should be designed in such a way that students can have a fruitful collaboration in this field, to build a knowledge infrastructure for secure, useful, and up-to-date sharing knowledge. The financial infrastructure should be designed in such a way that provides useful knowledge resources along with the required financial resources as well. In the end, in order to successfully manage the knowledge in the country's court of audit, it is recommended to the authorities to identify and take into the consideration of the set of factors in this research together so as to prevent the possibility of failure in the implementation of the KM system through adopting a systemic perspective.

\section{References}

1. Khakie, GH (2011). Research methodology with approach to writing dissertation (fourth edition). Tehran: Baztab Publication.

2. Salajegh, S and Nazerie, M (2008). The Role of Implicit KM in Creativity and Innovation. The first national conference on creativity and engineering and innovation management, Tehran.

3. Attarpour, Ali and Alinaghian, Nasrin (2009). An overview of intellectual capital measurement models. Journal of Management Tomorrow, Sixth Year, No. 20, pp. 25-35.

4. Ciara Heavin and Frederic Adam, (2013). "Exploring the Alignment of Organisational Goals with KM: Cases in Four Irish Software SMEs" The Electronic Journal Information Systems Evaluation Volume 16 Issue 1, (23-34), available online at www.ejise.com

5. Rivera, G., \& Rivera, I. (2016). Design, Measurement and Analysis of a Knowledge Management Model in the Context of University. Innovar, 26(59), 21-34. doi: 10.15446/innovar. v26n59.54320.

6. Kamath, G. B. (2008). Intellectual capital and corporate performance in Indian pharmaceutical industry. Journal of Intellectual Capital.9(4).684-704.

7. Kenneth C., Godday, O, Zechariahs, B. (2013). The Impact of Knowledge Management Capabilities on Organizational Performance: A Survey of the Service Sector. Journal of Business Management \& Social Sciences Research (JBM\&SSR) ISSN No: 2319-5614.Volume 2, No.9. 
